\title{
Personalitas Yesus dan Kritik terhadap Nestorius: Analisis Ibrani 4:12-14
}

The Personality of Jesus and Critique of Nestorius: Analysis of Hebrews 4:12-14

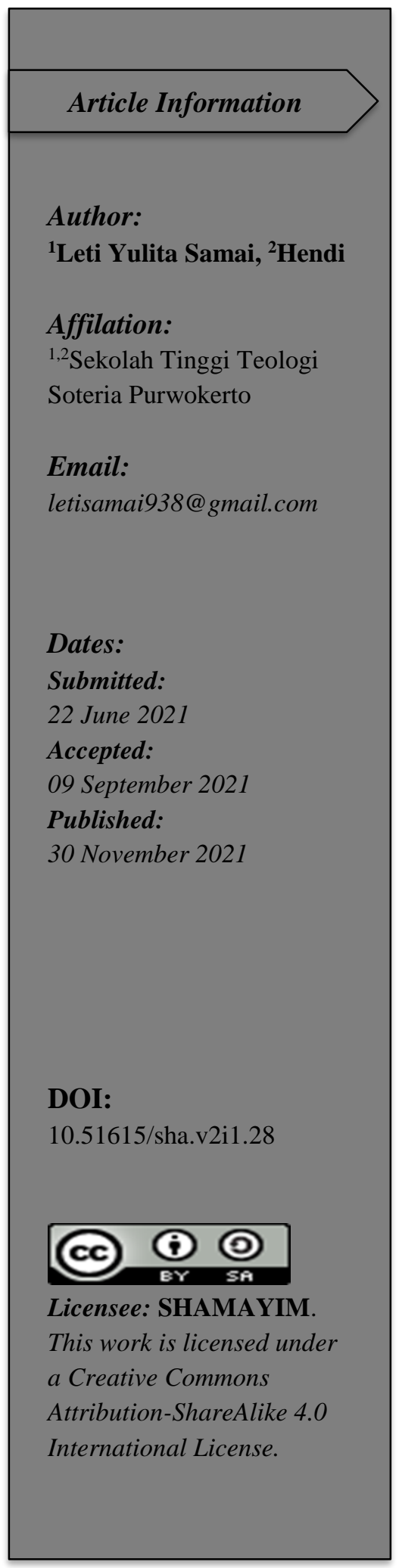

Abstract: The doctrine of the personal personality of Jesus Christ is still controversial today. Jesus Christ is the central figure and has the highest authority in Christianity, Jesus Christ is trusted by Christians because He is the Savior of all mankind, the proof that He is the Savior is through the Incarnation of the divine nature taking Mary's human nature so that Jesus Christ has two natures in His person namely, divine and human, the nature of Jesus is distinguishable but inseparable. However, a Christian figure in the fifth century, Nestorius, gave the opinion that Jesus Christ had separate divine and human natures in two distinct persons. It was Nestorius's teaching that became a major debate and rejection by Church fathers such as Cyril of Alexandria and rejected Nestorius's teaching in the Church. The author uses the method of text analysis or exegesis from Hebrews 4:12-14 which includes syntactic and semantic analysis, the semantic content will be analyzed by interacting with other texts such as the Bible and the writings of the Church Fathers. :12-14 to make comparisons with the teachings of Nestorius. Based on the results of the research in Hebrews 4:12-14 and the opinion of the church fathers, it shows that Nestorius' teaching is heresy and should not be accepted in the Church. Jesus Christ is fully God and human because in Him there are two natures or natures, namely divine and human and these two natures cannot be separated in two different persons, if the person of Jesus can be separated then He cannot die, rise and save all mankind and it is useless to believe in Him.

\section{Keywords: Jesus Christ, Nature, Nestorius}

Abstrak: Doktrin tentang personalitas pribadi Yesus Kristus masih menjadi kontroversi sampai zaman sekarang. Yesus Kristus adalah tokoh sentral dan memiliki otoritas tertinggi dalam Kekristenan, Yesus Kristus dipercaya oleh umat Kristiani karena Dia adalah Juruselamat bagi seluruh manusia, bukti bahwa Ia adalah Juruselamat yaitu melalui Inkarnasi natur keilahian menggambil natur kemanusiaan Maria sehingga Yesus Kristus memiliki dua natur dalam pribadi-Nya yaitu ilahi dan manusiawi, natur Yesus dapat dibedakan tetapi tidak bisa dipisahkan. Namun tokoh Kekristenan pada abad ke-lima yaitu Nestorius memberikan pendapat bahwa Yesus Kristus memiliki natur ilahi dan manusiawi yang terpisah dalam dua pribadi yang berbeda. Pengajaran Nestorius inilah yang menjadi perdebatan besar dan penolakan yang dilakukan oleh para bapa Gereja seperti Cyril dari Alexandria dan menolak pengajaran Nestorius dalam Gereja. Penulis menggunakan Metode analisis teks atau eksegesis dari surat Ibrani 4:1214 yang mencangkup analisis sintaksis dan semantis, isi semantis akan dianalisis dengan berinteraksi pada teks-teks lain seperti Alkitab dan tulisan para Bapa Gereja, Selanjutnya Penulis juga mengambil hasil teks eksegesis Ibrani 4:12-14 untuk menjadikan bahan perbandingan dengan ajaran Nestorius. Berdasarkan Hasil penelitian Ibrani 4:12-14 dan pendapat para bapa Gereja menunjukan bahwa pengajaran Nestorius adalah bidah dan tidak sepantasnya diterima dalam Gereja. Yesus Kristus sepenuhnya Allah dan manusia karena dalam diri-Nya terdapat kedua natur atau kodrat yaitu ilahi dan manusiawi dan kedua natur ini tidak dapat dipisahkan dalam dua pribadi yang berbeda, jika pribadi Yesus dapat dipisahkan maka Dia tidak dapat mati bangkit dan menyelamatkan seluruh umat manusia dan sia-sialah beriman kepada-Nya.

Kata Kunci: Yesus Kristus, Natur, Nestorius 


\section{Pendahuluan}

Doktrin tentang personalitas pribadi Yesus Kristus masih menjadi kontroversi sampai zaman sekarang. Sebab setiap orang memiliki hak dan kemampuan untuk menjelaskan pendapat atau pemahaman tentang pribadi Yesus Kristus, sehingga pemahaman-pemahaman inilah yang menjadi perdebatan umum di kalangan Kekristenan seperti pengajaran Nestorianisme. Nestorianisme adalah sebuah gerakan yang mengikuti ajaran Nestorius dari Antiokhia, Nestorius adalah tokoh pembela tradisi kristologis dan sekolah Teologi Antiokhia yang menekankan adanya dua kodrat terpisah dalam diri Yesus Kristus (duofisitisme). (Samuel Purdayanto. 2010) Pengajaran Nestorius ditolak dalam Gereja oleh para bapa Gereja pada tahun $451 \mathrm{AD}$, dalam Konsili Chalcedon, Gereja merumuskan pengertian pribadi Yesus Kristus yang terdiri dari dua natur ilahi dan manusiawi dan kedua natur ini tidak berubah, tidak terbagi, tidak terpisahkan, dan tidak bercampur. (Mulia. 1992) Khususnya bahwa pengajaran tokoh Kekristenanlah yang menyebabkan perpecahan dalam Gereja oleh sebab itu pengajaran-pengajaran seperti Natur Yesus harus kembali kepada Alkitab. Alkitab jelas mengajarkan identitas esensial Gereja sebagai persekutuan dan tubuh Kristus. (Jessica Novia Layantara. 2020) Kristologi bukan persoalan yang sederhana dan mudah untuk dimengerti ketika menemukan kekeliruan di dalamnya, diakhir abad ke-4 selain perdebatan mengenai kemanusiaan doktrin Allah, kotroversi lainnya adalah masalah Kristologi khususnya mengenai kemanusiaan dan keilahian Kristus. (Yohanes Verdianto. 2020) Ini menunjukkan bahwa ketika berbicara tentang Yesus memang pada dasarnya sangat misteri dan akan disalahpahami oleh beberapa kalangan tertentu. Tantangan bagi Kekristenan berhubungan dengan Kristologi bukan saja hanya memahami esensi Kristus sebagai Tuhan dan manusia tetapi juga membuktikannya melalui sumber kebenaran yaitu Alkitab.(Martin. 2018)

Yesus Kristus adalah tokoh sentral dalam Kekristenan yang memiliki otoritas tertinggi sebagai Juruselamat umat manusia. Dia disebut sebagai Juruselamat karena dasar iman Kristen adalah kebangkitan. (Kapan. 2007). Kebangkitan Yesus Kristus dari antara orang mati menunjukkan bahwa Dia sepenuhnya Allah dan manusia, melalui kebangkitan-Nya Dia telah mengalahkan kutuk, iblis dan maut sehingga disebut sebagai Juruselamat dunia. Hidup dalam kebangkitan Yesus itu berarti keinginan dosa dan iblis telah dikalahkan dan memulai hidup baru dalam kemenangan. (Kapan. 2007). Pada dasarnya kita manusia telah mengalami hidup baru bersama dengan Yesus melalui kebangkitan-Nya namun pribadi-Nya masih belum dipahami dengan jelas, jika natur-Nya hanyalah manusia maka Dia tidak akan bangkit begitupun sebaliknya hanya memiliki natur ilahi maka tidak dapat mati. Oleh karena itu, Yesus Kristus memiliki dua natur yaitu ilahi dan manusia yang tidak dapat dipisahkan dalam diri-Nya karena telah menyatu dalam satu kesatuan.

Dengan demikian paham yang bertolak belakang dengan pengajaran para saksi mata tentang pribadi Yesus Kristus dapat memberikan kesalahpahaman dalam Kekristenan. Oleh sebab itu setiap orang percaya harus benar-benar mengetahui pengajaran yang benar tentang natur Yesus Kristus melalui pengajaran para saksi mata yang menyaksikan kehidupan Yesus dari lahir sampai mati dan ditulis dalam Alkitab orang Kristen. Dalam Matius 7:115, Rasul Paulus mengatakan bahwa "karena kita hidup di dunia yang selalu berdampingan dengan orang baik dan jahat dan sama-sama mengajarkan Injil Kristus maka waspadalah dan berjaga-jaga. Artinya baik ajaran benar maupun salah selalu berdampingan dalam Gereja sehingga salah mengerti pengajaran Gereja yang benar maka akan terjebak dalam pengajaran yang menyesatkan dan dapat mempengaruhi umat. Dengan demikian dalam penulisan artikel ini, penulis akan menjelaskan tentang tinjauan personalitas Yesus Kristus menurut Ibrani 4:12-14 dan kritik terhadap pengajaran Nestorius, kemudian menggunakan ide-ide penolakan terhadap pandangan paham Nestorianisme oleh para bapa Gereja seperti Cyril dari Alexandria. 


\section{Metode Penelitian}

Penulisan ini menggunakan metode penelitian eksegesis dari Surat Ibrani 4:12-14, Eksegegis sendiri berasal dari bahasa Yunani yaitu exegomai yang artinya dalam bentuk dasarnya ialah "membawa keluar" atau "mengeluarkan" dengan kata benda "tafsiran" atau "penjelasan", yang diambil dari (The Greek New Testament Nestle-Aland 28th Edition of the Greek New Testament). Melalui eksegesis ini, penulis akan mendapatkan inti pesan yang sesungguhnya dalam teks tersebut yakni dengan menemukan theoria dalam semantic content berupa isi semantis atau makna spiritual meaning di balik teks tersebut sehingga untuk menemukan makna spiritual, semantic content atau isi semantic dibangun dari historia dengan cara membuat syntatic form (sturktur teks dalam bahasa Yunani) dan terjemahan literal untuk mendapatkan poin-poin sintaksis (syntatic content), isi semantis akan dianalisis dengan berinteraksi pada teks-teks lain seperti Alkitab dan tulisan para Bapa Gereja. Selanjutnya Penulis juga mengambil hasil teks eksegesis Ibrani 4:12-14 untuk menjadikan bahan perbandingan dengan ajaran Nestorius tentang pribadi Yesus Kristus dan ide-ide pendukung tentang penolakan paham Nestorius dari para Bapa Gereja seperti Cyril dari Alexandria.

\section{Hasil dan Pembahasan}

\section{Paham Nestorianisme tentang Pribadi Yesus Kristus}

Paham Nestorianisme adalah paham yang dipimpin oleh Nestorius, pengajaran-nya bertentangan dengan Gereja dan secara ekstrem telah mengusik kepercayaan agama-agama lain termasuk Kristen, karena persoalannya menyangkut esensi dari Kekristenan yang terkait kesepakatan iman bersama. (Andrew Stephen. 2011). Iman orang Kristen tujuannya kepada Yesus Kristus yang telah bangkit dari antara orang mati dan itu menunjukkan bahwa Ia adalah Tuhan dan Juruselamat sehingga esensi-Nya harus dipahami dengan benar oleh seluruh orang percaya karena bersangkutan dengan iman.

Abad 1 dan 2 pandangan tentang pribadi Yesus masih cukup baik akan tetapi memasuki abad ke-5 muncul-lah berbagai pengajaran sesat tentang Yesus yang diajarkan oleh tokoh Kekristenan seperti Nestorius. Pengajarannya ini dianggap bidah atau sesat oleh para bapa Gereja. Nestorius adalah seorang Uskup Konstantinopel dari Antiokhia di Syria dan pernah mengikuti pendidikan dengan Theodore dari Mopsuestia, ia juga termasuk seorang mahasiswa Kristen dari ahli retrotika pangan, lalu kaisar Theodosius II melantik Nestorius sebagi uskup kota kekaisaran pada tahun 428 sebagai pendukung setia Kristologi sifat ganda Antiokhia. (Wessel. 2004). Dengan demikian dapat dikatakan bahwa Nestorius adalah seorang yang pintar pada saat itu karena dia dibesarkan dengan didikan yang hebat dan hidup dengan orang-orang pintar pada abad itu, sehingga setelah pentabisan menjadi Uskup Kekaisaran dan menggambil bagian sebagai pendukung ajaran Antiokhia tentang pengajaran Kristologi ganda ia mengemukakan pendapat bahwa "Yesus Kristus memiliki dua natur ilahi dan manusia yang terpisah". Namun pengajaran inilah yang ditolak dalam Gereja karena menurut pandangannya Yesus Kristus memiliki dua natur dalam dua pribadi yang berbeda, dalam pengertian bahwa natur kemanusiaan dan ilahi itu terpisah dalam pribadi yang berbeda. Kepribadian ganda atau menyangkal kesatuan nyata hakikat ilahi dan manusia Yesus Kristus dengan menyatakan bahwa logos (kepribadian ilahi) berada di dalam Kristus (kepribadian manusiawi). (Phillips Takaliuang. 2020). Nestorius telah menyangkal esensi Yesus dengan pandangan-nya sendiri dan memengaruhi orang percaya lain agar percaya kepada pengajaran-nya.

Natur Yesus yang diajarkan oleh Nestorius ini ditantang oleh Cyril dan menyebutkan bahwa pengajaran Nestorius itu adalah sesat dan menurut Cyril kodrat manusiawi dan keilahian Yesus sangat erat terikat bersama menjadi satu sifat inkarnasi dari Firman Tuhan. (Wessel. 2004). Maksud penjelasan Cyril 
adalah natur Yesus tidak terpisahkan dalam dua pribadi yang berbeda karena sangat terikat dalam satu kesatuan yaitu Firman Allah telah berinkarnasi melalui perawan Maria untuk menggambil natur kemanusiaan-Nya sehingga natur ke-Allahan dan kemanusiaan menyatu dalam pribadi yang satu yaitu Yesus Kristus. Lalu Cyril berkomentar pada konsili di Efesus dan menyebutkan Nestorius sebagai seorang pemimpin yang bodoh dan menjijikan karena tidak mengerti tentang misteri benar, sakral dan mendalam dari inkarnasi Putra Tunggal sehingga dengan mudah dapat melakukan penghujatan. (Wessel. 2004). Oleh karena itu, pengajaran Nestorius dianggap penghujatan terhadap Kristologi sehingga ajarannya tentang natur Yesus ditolak dalam Gereja karena pengajaran tersebut akan mempengaruhi pola pikir orang percaya untuk percaya kepada ajaran sesat.

Dalam satu pribadi Yesus Kristus ada dua hakikat yaitu ilahi dan manusiawi yang dapat dibedakan tetapi tidak dapat dipisahkan. (Adrianus Pasasa. 2014). Sama seperti sebuah ilustrasi harum bunga bakung dimana didalam bunga tersebut terdapat harum bakung, dimana dapat dibedakan harum dan bunga tetapi tidak dapat dipisahkan. Ini sama seperti natur ke-manusiaan Yesus dapat dilihat namun keilahian-Nya tidak dapat dilihat karena berada dalam diri Yesus sehingga dapat dibedakan natur tetapi tidak bisa dipisahkan karena berada dalam satu kesatuan. Eutychus juga mengatakan bahwa didalam diri Kristus kedua sifat itu menjadi satu, yang menekankan kembali bahwa Kristus memiliki dua sifat ilahi yang menyatu atau hypostasis. (Kunto. 2021). Artinya dalam diri Yesus Kristus ada dua natur yaitu ilahi dan manusia, naturNya tidak dapat dipisahkan karena telah menyatu dalam diri-Nya, dalam pengertian bahwa bukan Firman atau Logos Allah yang menjadi dua kali lipat akan tetapi dalam satu kesatuan dimana natur ilahi dan manusia berada dalam diri-Nya dan terdapat karakteristik Allah.

Pada tahun 451 Masehi, dalam konsili Chalcedon meneguhkan bahwa Yesus Kristus adalah benarbenar manusia dan benar-benar Allah, kedua natur dari Yesus Kristus merupakan suatu kesatuan yang tanpa pencampuran. (Wessel. 2004). Natur Yesus adalah ilahi dan manusia, dimana natur kemanusiaan-Nya dapat mati dan keilahian-Nya membangkitkan. Yesus disalibkan dan mati ini menunjukkan bahwa Ia memiliki tubuh jasmani dengan merasakan rasa sakit dan tidak dapat dipisahkan dengan natur keilahian-Nya (Matius 26:26, 28; Ibrani 2:14) maupun jiwa atau roh (Matius 26:38) memiliki pikiran manusia (Matius 24:36; Lukas 2:40,52) perasaan manusia, kehendak manusia, dan juga mengalami apa yang manusia alami atau rasakan (Lukas 2:7; Matius 4:2; Yohanes 4:7; 19:28; Yohanes 4:6; Matius 8:24: Ibrani 2:10,18; Yohanes 19:30). (Adrianus Pasasa. 2014). Agar dipahami bahwa kedua natur Yesus tidak dapat berdiri sendiri. Ranto mengatakan bahwa konsep Yesus Kristus adalah pre-eksisten, Allah sejak dalam kekekalan, Yesus sepenuhnya Allah dan berinkarnasi mengambil rupa sebagai manusia dan menjadi manusia sejati tanpa berhenti sebagai Allah. (Ranto. 2019).

\section{Yesus Kristus adalah Firman Allah yang Hidup}

Alkitab adalah tulisan para saksi mata yang masih digunakan oleh Gereja sampai saat ini, melalui Alkitab-lah Firman Allah itu diberitakan serta memberikan pemahaman kepada Gereja tentang Yesus Kristus dan karya keselamatan-Nya. Karya keselamatan Yesus inilah memiliki tujuan bagi orang percaya agar menjadi serupa dengan Yesus Kristus dan memiliki gambar dan rupa Allah yang didalam-Nya terdapat natur ilahi dan manusia dengan mengandung kebenaran (Yohanes 14:6) untuk mengetahui tentang Allah harus melalui Kristus karena Dia adalah jalan dan kebenaran.

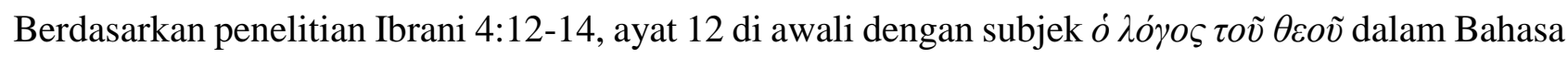
Inggris the word of God yang artinya Perkataan/Firman Allah, selanjutnya menjelaskan predikat inti $Z \tilde{\omega} v$ 
yang artinya live atau hidup yang artinya Firman Allah itu hidup sehingga dalam (Kejadian 1; Mazmur 33:6) juga mencatat bahwa sebelum dunia diciptakan Firman itu telah ada bersama-sama dengan Bapa dalam pengertian bahwa memiliki satu kodrat Allah sendiri (Yohanes 1:1) dan menciptakan alam semesta pada mulanya agar memberikan kehidupan kepada segala ciptaan manusia. (Ware. 2020). Yesus disebut sebagai Anak Allah bukan karena wujud kemanusiaan-Nya namun keberadan-Nya sebagai Firman (Yohanes 1:14; 14:8) sebelum bayi Yesus dilahirkan oleh Maria (Yohanes 17:5). (Ware. 2020). Ini memberikan pengertian bahwa pada mula-Nya Yesus adalah Firman hidup yang telah bersama-sama dengan Bapa dan memiliki natur ilahi dan manusia. Kemudian Firman Allah itu berinkarnasi menjadi manusia mengambil rupa kemanusiaan agar manusia mengetahui pola ciptan-Nya sehingga hidup benar di hadapan Allah, namun kehadiran Yesus Kristus kedunia di salah mengerti oleh berbagai ajaran lainnya seperti Nestorianisme yang mengajarkan bahwa keilahian dan kemanusiaan Yesus terpisah dalam dua pribadi bukan satu.

Hendi dalam bukunya mencatat bahwa "Yesus Kristus adalah Firman Allah yang hidup dan menjadi manusia (Yohanes 1:14) memiliki dua natur yaitu ilahi dan manusia (Keluaran 2:9) dan jika Dia adalah Firman Allah yang hidup berarti Firman memiliki sumber yang membawa Dia keluar dan berinkarnasi. (Hendi Wijaya. 2020). Artinya segala kuasa yang dimiliki oleh Yesus Kristus ialah bersumber dari Allah sendiri yang adalah Bapa, sehingga ketika menjadi manusia menunjukkan natur kemanusiaan-Nya yang lahir dari perawan Maria. Bapa adalah sumber dari segala sesuatu, berada di luar ruang dan waktu dan Bapa adalah Roh, sehingga Bapa mengutus Firman-Nya/Logos agar berinkarnasi menjadi manusia dan menunjukkan siapa Allah, agar mengetahui siapa Allah yaitu melalui pengenalan akan Firman yang hidup atau Yesus Kristus. Kemudian Hendi juga mengatakan bahwa "Yesus disebut Anak Allah bukan dalam wujud kemanusiaan-Nya melainkan dalam keberadaan-Nya sebagai Firman (Yohanes 1:4; 18). Yesus Kristus sebelum menjadi manusia Dia dikandung dalam diri Allah sebagai akal budi dan logos yang berada dalam diri Allah. (Hendi. 2019). Pemahaman manusia tentang dikandung berbeda dengan pemahaman Allah, karena Allah adalah roh tidak mungkin Allah mengandung Yesus seperti seorang ibu mengandung anak dalam rahimnya. Oleh karena itu, untuk mengerti tentang Kristologi adalah misteri Allah yang tidak dapat dijelaskan melalui pemahaman sendiri.

Yesus Kristus sebagai Allah sejati dan manusia sejati, satu pribadi di dalam dua kodrat yaitu kodrat Allah dan manusia tanpa terpisah dan bercampur baur. (Hendi. 2019). Dua kodrat yang dimiliki Allah tidak dapat dipisahkan karena telah menyatu dalam satu pribadi yaitu Yesus Kristus, sehingga manusia diciptakan menurut gambar dan rupa Allah melalui pribadi Yesus karena dalam diri Yesus berdiam segala kepenuhan Allah (Kolose 1:19;12:9). Yesus Kristus memiliki dua natur yaitu ilahi dan manusia dan ketika menjadi manusia bukan berarti keilahian-Nya hilang. (Stt \& Purwokerto. 2018). Artinya natur ilahi dan manusia telah menyatu dalam pribadi Yesus, inkarnasi Firman hidup untuk menjadi manusia dengan sukarela menerima kemanusiaan-Nya dengan haus, lapar, lelah dan pada akhirnya mati di atas Kayu salib, ini menunjukkan bahwa Ia adalah Imam Agung. Yesus Kristus memiliki dua natur yaitu ilahi dan manusia dan pada saat Yesus menjadi manusia melalui inkarnasi Maria bukan berarti keilahian-Nya hilang tetapi dalam diri-Nya telah memiliki kepenuhan ilahi dan manusia. (Stt \& Purwokerto. 2018).

Firman yang hidup di utus Allah datang kedunia agar setiap orang yang percaya kepada-Nya mengalami kehidupan yang kekal, sehingga setiap orang yang percaya kepada Dia akan hidup oleh Kristus di dalam Bapa. (Stt \& Purwokerto. 2018). Tujuan kedatangan Sang Firman Allah ialah menunjukkan siapa Allah dan bagaimana cara mengalami kehidupan yang kekal yaitu melalui percaya dan beriman kepada Yesus agar mengalami kehidupan kekal bersama dengan Allah. Firman yang hidup dan penuh kuasa pada 
penjelasan selanjutnya mengatakan bahwa perkataa-Nya lebih tajam dari pedang bermata dua, menebus kedalaman jiwa, roh, sendi dan sum-sum (Matius 28:18). Allah memberikan segala kuasa di surga dan di bumi kepada Yesus yang telah bangkit, maka Allah pulalah yang mengangkat Yesus menjadi Tuhan dan penguasa mutlak atas Surga dan bumi. (Ware. 2020). Ini menunjukkan bahwa kuasa yang dimiliki Yesus Kristus berasal dari sumber kehidupan yaitu Allah karena diberikan kuasa di surga dan bumi. Oleh sebab itu Kristus memiliki dua natur ilahi dan manusia yang dapat mengetahui keadaan manusia dengan natur ilahi-Nya.

Yesus Kristus berkuasa dalam diri orang, karena jiwa dan roh manusia berasal dari napas Allah. Yesus Kristus ialah Firman hidup yang telah diberikan kuasa oleh Allah sebelum dunia dijadikan, karena pada mulanya Bapa dan Firman bersama-sama menciptakan dan telah diberikan kuasa kepada Anak Tunggal (Yohanes 3:35). Ini membuktikan bahwa Bapa mengasihi Anak dan telah menyerahkan segala sesuatu kepada-Nya. Oleh sebab itu kasih Bapa telah memberikan kepercayaan kepada Anak Tunggal-Nya yaitu Kristus untuk memiliki kuasa baik di bumi dan dalam kekekalan (Yohanes 13:3) sehingga kuasa yang telah diberikan kepada Allah lebih tajam dari pedang bermata dua, akan menusuk kedalaman dan dapat memisahkan jiwa dan roh, tidak ada satu makhluk pun yang tersembunyi dari-Nya, tidak ada kuasa yang dapat mengalahkan kuasa Allah, kuasa yang begitu kuat dan besar. Ketika Yesus telah dimuliakan sebutan Kyrios atau Tuhan menunjukkan kepada Yesus yang memiliki makna sebagai "penguasa" atau yang dipertuan Jadi kata Kyrios tidak langsung menunjukkan kepada Allah (Theos) karena Kyrios atau Tuhan menunjuk kepada Yesus. (Ware. 2020). Yesus Kristus mendapatkan hidup kekal (Rm. 5:21; Yoh 17:2), karena Kristus telah diberikan kuasa Allah dan membawa manusia kepada Allah, untuk mengenal Allah yang benar sebab itu Dia adalah satu-satunya jalan kepada Allah (Yoh. 14:6-7). (Hendi, 2019). Yesus dapat berkuasa dalam roh dan jiwa manusia karena memiliki natur ilahi sehingga mengetahui kedalaman hati manusia.

\section{Yesus Kristus sebagai Imam Besar Agung}

Yesus Kristus adalah seorang Imam yang menjadi tokoh sentral Kekristenan yang memiliki kisah dimulai dari Inkarnasi, pelayanan, sampai kepada kebangkitan, pada saat Dia bangkit di situlah Dia menunjukkan natur keilahian dalam pribadi-Nya serta membawa orang lain berbalik dan percaya kepadaNya. Surat Ibrani menulis bahwa Yesus Kristus adalah Imam Agung besar yang melintasi seluruh bumi dan kepada Dia memberikan pertanggung jawab dan berpegang kepada pengakuan iman kepada Yesus Kristus. Jabatan keimaman Yesus Kristus berasal dari Allah. Seorang Imam tidak hanya memakai kemuliaan yang di anugerahkan Allah pada dirinya saja, melainkan juga berlaku di surga oleh sebab itu Ia disebut sebagai imamat rajani. (Jihole \& Tinggi Teologi Soteria Purwokerto. 2020). Imamat rajani ialah imam yang diberikan tanggung jawab khusus dari Allah kepada Yesus karena Ia adalah Imam yang berasal dari Allah. Yesus Kristus adalah Imam terakhir yang memiliki kuasa di bumi dan surga yang kedatangan-Nya dinubuatkan dalam Perjanjian Lama (Kisah Para Rasul 17:3; 18:5). Sejarawan sekuler dari Roma yang bernama Tacitus (112 M) dan juga Yosefus sejarawan Yahudi abad pertama yang mengatakan bahwa memang adanya seorang tokoh yang pernah hidup bernama Yesus Kristus. (Henry C. Thiessen. 1992). Menunjukkan bahwa kehidupan Yesus Kristus bukan cerita fiktif akan tetapi kisah nyata yang tercatat dalam buku sejarah.

Yesus Kristus memiliki kuasa sebagai Imam Agung Besar dengan memiliki natur ilahi dan manusia yang berada dalam diri-Nya. The fact Jesus is a great high priest will enable the readers to remain true; 
the exhortation implies their tendenci to waver, great here suggests the uniqueness of this particular prossesor of that exalted office, this indeed is no ordinary high priest, he is the man Jesus, but also the unique son of God, the one who has gone through the heavens, this last clause my be an allusion to Christ's presence in the spiritual of "heavenly temple" where his priestly works is accomplieshed. (Donald A. Hagner. 2011). Dalam pengertian bahwa Yesus Kristus adalah Imam Agung yang diagungkan dan dimuliakan dengan jabatan tertinggi yang dimiliki-Nya, kerena itu Yesus Kristus disebut sebagai anak Allah yang unik dari antara keseluruhan manusia, di mana dapat menjelaskan diri-Nya dan pribadi Allah yang adalah roh.

Tugas Imam Agung ialah menyampaikan Firman Allah kepada seluruh manusia dan membawa orang-orang untuk masuk ke hadirat Allah, dengan demikian seorang Imam harus benar-benar mengenal manusia dan Allah, Yesus sebagai Imam Agung bukan karena kehormatan yang diberikan manusia atau karena perhiasan lahiriah melainkan karena hakikat diri-Nya sendiri. (Wiliam Barclay. 2008). Yesus adalah seorang Imam yang seharusnya dihormati karena Dia adalah Imam Allah karena dalam diri-Nya terdapat kepenuhan Allah, kepenuhan Allah dalam diri-Nyalah membuat Dia rela berkoraban serta menyelamatkan manusia karena Allah adalah kasih. Chrysostom dengan tegas mengatakan bahwa jabatan seorang imam adalah mulia, Seorang imam telah menerima otoritas untuk menangani kenajisan rohani, menyelamatkan jiwa yang sakit dan memiliki otoritas untuk mengampuni dosa dengan berdoa untuknya, mengurapinya dengan minyak didalam Tuhan. (Cahyani. 2021).

Imam juga harus mendedikasikan pemurnian jiwa bukan hanya untuk diri-nya sendiri melainkan kepada pengikutnya, tidak hanya berfokus pada relasinya dengan Tuhan tetapi bagaimana seorang Imam bisa menghidupkan kebenaran Kristus dalam mengajarkan kepada jemaat bahwa Kristus adalah satusatunya jalan keselamatan. (John Chrysostom). Keselamatan adalah karya Allah Tritunggal, bukan manusia (Efesus 2:8-10). (Stevanus. 2020). Oleh karena itu, yang dapat menyelamatkan manusia Adalah Allah. Yesus bukan hanya menjadi Imam besar orang Yahudi, tetapi juga sebagai korban persembahan yang kekal dan sempurna, terlebih sebagai Imam besar dan korban persembahan untuk seluruh umat manusia. (Peter Wongso. 1997).

Berbagai perspektif yang berbeda-beda dan mengatakan bahwa Yesus ialah Imam besar orang Yahudi, karena memang pada saat itu Yesus Kristus berada di daerah tersebut namun Yesus Kristus telah menjadi Imam Besar bagi seluruh umat yang percaya dan beriman kepada-Nya. Yesus Kristus bukan hanya menjadi seorang Imam bagi kalangan tertentu tetapi bagi seluruh umat manusia. Dia bertugas sebagai seorang Imam dan menyampaikan Firman Allah kepada seluruh umat manusia dengan membawa ke dalam hadirat Allah, sehingga Imam Agung harus memiliki pengenalan yang serius kepada manusia dan sekaligus pengenalan kepada Allah, Ia menjadi seorang Imam bukan hanya pribadi-Nya ini yang membuat Dia lebih mengenal Allah akan tetapi karena hakikat-Nya sendiri, (Wiliam Barclay. 2008). Dalam pengertian bahwa untuk pengenalan kepada Allah, Yesus adalah Allah yang sejati, dan untuk pengenalan kepada manusia Dia telah berinkarnasi dan menjadi manusia, sehingga Dia dapat mengerjakan pelayanan sebagai seorang Imam. Gregorius mengatakan bahwa perbuatan seorang imam yang buruk akan mengotori air yang diberikan kepada para domba-domba. (Gregorius the Great. 2017).

Gerkin, seorang yang meneruskan tradisi berpikir Perjanjian Lama dengan mengatakan bahwa Yesus Kristus memang sepantasnya menyebutkan diri-Nya sebagai seorang Imam yang baik karena mampu melaksanakan seluruh peran dan fungsi Nabi, Imam dan orang berhikmat secara bertanggung jawab. (Messakh. 2018). Artinya Yesus adalah seorang Imam dengan memiliki semua peran sebagai seorang pemimpin dengan bertanggung jawab, mengorbankan diri-Nya demi umat kepunyaan agar mereka 
disucikan oleh Allah. Seorang Imam dapat menyentuh jiwa domba-dombanya, yaitu dengan kasih. Chrysostom menjelaskan bahwa dari semua pendekatan, strategi atau cara yang paling utama yaitu kasih. (John Chrysostom). Kasih adalah salah satu bahasa kasih yang dapat dilakukan oleh siapa pun kepada orang yang Dia kasihi, seperti Yesus yang adalah seorang Imam memberikan kasih kepada seluruh umat manusia dengan mengorbankan diri-Nya, inilah kasih yang membuat banyak orang mencintai dan mengingat Dia sebagi seorang Imam yang memberikan teladan baik.

Pribadi Yesus juga bukan sekadar manusia biasa namun ilahi, sehingga Paulus mengatakan bahwa Dia adalah Juruselamat kita (Flp. 2:6; Tit. 2:13). Milar J. Erickson mengatakan bahwa karya pengorbanan Kristus digambarkan sebagai seorang Imam Besar Agung yang telah masuk ke dalam tempat kudus agar mempersembahkan korban yaitu tubuh dan darah-Nya sendiri bukan hewan. (Maria Widiastuti. 2020). Yesus adalah seorang Imam yang membawa persembahan kepada Allah yaitu tubuh-Nya untuk menjadi penebus atas dosa dan kesalahan umat manusia, pribadi Yesus dengan karya-Nya tidak dapat dipisahkan karena berkaitan erat, Dia adalah Firman dan manusia sepenuhnya yang sudah dulu ada sebelum dunia diciptakan (Yoh. 1:1-5) dengan rendah hati mengambil rupa manusia hanya untuk menyelamatkan manusia dari dosa, kutuk dan maut.

Penulis Kitab Ibrani mengatakan dalam pasal 4:12-14 bahwa Yesus Kristus adalah Firman Allah yang hidup sama seperti yang di di tulis dalam Injil Yohanes 1:1, kemudian Firman Allah yang hidup ini menjelaskan bahwa Firman yang hidup dan penuh kuasa, Dia hidup dengan memiliki kuasa baik di Surga dan bumi sehingga mengetahui kedalaman hati dan pikiran manusia dan menjadi hakim, segala sesuatu terbuka dan telanjang di depan mata Dia. Ini menunjukkan bahwa kuasa yang dimiliki Yesus bukan hanya di dalam dunia akan tetap dalam kekekalan sekalipun Dia berkuasa, untuk memahami tentang pribadi Yesus Kristus yang benar harus meminta tuntunan dan pengertian dari Roh Kudus, Rasul Yohanes pernah mengatakan bahwa "jika salah memahami tentang Kristus maka kita bukan berasal dari Allah, karena ada roh-roh yang bukan berasal dari Allah dan ujilah roh itu (1 Yohanes 4:1). Karena itu beragama Kristen saja tidak cukup untuk memahami tentang siapa Yesus Kristus? tetapi perlu mengetahui pengajaran yang benar tentang diri-Nya dan memberikan pengajaran benar tentang diri-Nya melalui ajaran lurus karena dalam Filipi 3 juga mencatat bahwa "akan ada pengajaran-pengajaran palsu dan memang sudah ada dunia". Oleh sebab itu, orang percaya harus mengetahui ajaran yang benar dan mencapai kehidupan kekal bersama kebenaran itu sendiri yaitu Yesus Kristus.

Sebelum dunia dijadikan, Firman telah ada bersama-sama dengan Bapa dan menciptakan segala sesuatu (Yoh. 1:1). Firman berinkarnasi menjadi manusia, sehingga Dia memiliki natur manusia dan ilahi dalam diri-Nya dan tidak dapat dipisahkan karena keilahian berasal dari Allah yang telah menyatu dengan diri-Nya kemudian natur manusia juga menyatu dalam diri Yesus, sehingga kedua natur tidak dapat dipisahkan; jika dipisahkan berarti Yesus Kristus tidak dapat menderita di kayu salib, mati, dan bangkit, dan disebut sebagai Tuhan dan Juruselamat. Dalam Filipi 2:6-8 dituliskan bahwa Firman itu mengambil rupa seorang hamba, yang mengatakan bahwa Dia mengambil sifat manusia, ini dapat menjelaskan bahwa Yesus Kristus bukan hanya berasal dari Allah akan tetapi Dia telah hadir ke dunia dengan mengambil rupa seorang hamba dan menunjukan diri-Nya memiliki sifat manusia.

\section{Kesimpulan}

Nestorius mengajarkan bahwa Yesus Kristus memiliki dua natur natur ilahi dan manusia yang terpisah atau berbeda pribadi. Akan tetapi penulis berargumen bahwa Yesus Kristus bukan hanya memiliki 
dua natur akan tetapi kedua natur yang dimiliki Yesus Kristus berada dalam diri-Nya atau menyatu dalam pribadi-Nya dan tidak dapat dipisahkan, dengan alasan bahwa Yesus Kristus adalah Firman Allah (Yohanes 1:1; Ibrani 4:12) di mana telah bersama-sama dengan Allah dan dalam diri-Nya terdapat kepenuhan Allah (Yoh 1:1; Ibrani 4:12). Ia telah bersama-sama dengan Allah dan dalam diri-Nya terdapat kepenuhan Allah, disatu sisi Yesus telah menggambil rupa manusia dengan berinkarnasi melalui perawan Maria bahwa Ia telah sepenuh-Nya menggambil natur ilahi dan manusia dalam pribadi-nya dan tidak dapat dipisahkan tetapi dapat dibedakan. Oleh karena itu, pandangan Nestorianisme tentang natur Yesus sangat keliru dan telah ditolak dalam Gereja, Yesus memiliki natur ilahi dan manusia sehingga dapat menyelamatkan seluruh umat manusia dan disebut sebagai Juruselamat. Dengan demikian Yesus Kristus adalah Firman Allah (Yohanes 1:1) yang berasal dari Allah kemudian Ia harus menjadi manusia agar menyelamatkan manusia dari dosa, iblis dan maut sehingga Ia menggambil natur kemanusiaan-Nya dari seorang perawan Maria dan menunjukkan bahwa Ia sepenuh-nya Allah dan manusia.

\section{Referensi}

Adrianus Pasasa. (2014). Mengalami Perjumpaan dengan Tuhan Yesus melalui Pribadi dan KaryaNya. Jurnal Teologi Dan Pengembangan Pelayanan, 4.

Andrew Stephen. (2011). Evans, Sejarah Bidah (Jakarta: Bpk Gunung Mulia, 2011), ix.

Cahyani, E. N. (2021). Kemuliaan Jabatan Seorang Imam Menurut John Chrysostom. 4(1), 100-117.

donald A. Hagner. (2011). Hebrrews. Bakerbooks.

Gregorius the Great. (2017). The Book of Pastoral. St. Vladmir's Seminary Press.

Hendi. (2019a). Inspirasi Kalbu 3. 180.

Hendi. (2019b). Pandangan Pengakuan Iman Nicea-Konstantinopel (Kredo Nicea) Tentang Doktrin. Jurnal Teologi Cultivation, Vol.3, 10-11.

Hendi Wijaya. (2020). Inspirasi Kalbu 4. LeutikaPrio.

Henry C. Thiessen. (2010). Teologi Sistematika (Cetakan Ke). Penerbit Gandum Mas Malang.

Jessica Novia Layantara. (2020). Relevansi Pemikiran Émile Durkheim terhadap Usaha Revitalisasi Gereja

Protestan Masa Kini. Veritas: Jurnal Teologi Dan Pelayanan, 19(2), 135-150. https://doi.org/10.36421/veritas.v19i2.364

Jihole, D. S., \& Tinggi Teologi Soteria Purwokerto, S. (2020). Cultivation (Vol. 4, Issue 2).

John Chrysostom. (n.d.). Book On the Priesthood. English Translation by Graham Neville.

Ka'pan, P. (2007). Kebangkitan Yesus Kristus Dasar Iman Kristen. Jurnal Jaffray, 5(1), 7. https://doi.org/10.25278/jj71.v5i1.121

Kunto, P., Sekolah, B., Anugerah, T. T., \& Semarang -Surakarta, A. (2021). Apologi Biblikal Atas Tuduhan Yesus, Manusia Yang Di-Tuhankan. Jurnal Teologi Dan Pendidikan Agama Kristen, 3(2).

Maria Widiastuti. (2020). Pemahaman Kristologi bagi Guru PAK. Pendidikan Agama Kristen, Vol.7 No.3, 93.

Martin, R., Sekolah, S., Agama, T., Teruna, K., \& Yogyakarta, B. (2018). Jurnal Teruna Bhakti. In Copyright@.

Messakh, B. J. T. (2018). Menuju Pelayanan Pastoral yang Relevan dan Kontekstual. Jurnal Teologi Dan Pendidikan Agama Kristen, Vol. 1, No, 24.

Mulia, H. G. (1992). Sejarah dan Tinjauan Kritis Terhadap Teori Kenosis. Jurnal Pelita Zaman, 7(1), 5967.

Paradoks Inkarnasi: Allah Yang Kekal Menjadi Manusia Sejati (Yoh.1:1-14; Flp. 2:1-11). (n.d.). 
Peter Wongso. (1997). Ibrani.

Phillips Takaliuang, M., Kunci, K., Sesat, A., \& O. (2020). Missio Ecclesiae Ancaman Ajaran Sesat di Lingkungan Kekristenan: Suatu Pelajaran Bagi Gereja-Gereja di Indonesia. 9(1), 163-184.

Samuel Purdayanto, F. E. S. (2010). Jurnal Teologi Dan Pendidikan Kristen Kontekstual. Jurnal Teologi Dan Pendidikan Kristen Kontekstual, 1(1), 1.

Stevanus, K. (2020). Karya Kristus Sebagai Dasar Penginjilan di Dunia Non-Kristen. 3(1), 1-19.

Stt, H., \& Purwokerto, S. (2018). Formasi Rohani : Kata Pengantar.

Ware, T. (2020). Gereja Orthodoxi. Padepokan Dharma Tuhu.

Wessel, S. (2004). Cyril Of Alexandria And The Nestorian Controversy. Oxford Early Christian Studies. Wiliam Barclay. (2008). Pemahaman Akitab Setiap Hari:Surat Ibrani. BPK Gunung Mulia.

Yohanes Verdianto. (2020). No Title. Fakultas Teologi, Universitas Halmahera, Maluku Utara, 4, 273 282. 